\title{
Hubungan Antara Mindfulness dengan Kepuasan Hidup Mahasiswa Bimbingan dan Konseling
}

\author{
Pranazabdian Waskito, J.T. Lobby Loekmono, Yari Dwikurnaningsih \\ Program Studi Bimbingan dan Konseling, Fakultas Keguruan dan Ilmu Pendidikan, \\ Universitas Kristen Satya Wacana, Jl. Diponegoro No. 52-60, Salatiga, Jawa Tengah, Indonesia 50711 \\ E-mail: waskito.prana@gmail.com
}

Artikel diterima: 2 Mei 2018; direvisi: 6 Agustus 2018; disetujui: 16 Agustus 2018

\begin{abstract}
The research aimed at identifying the relation between mindfulness and life satisfaction among guidance and counseling students. The research was a correlational study using Kendall's Tau-b correlation analysis technique. The respondents were 135 students from the Guidance and Counseling Study Program, Faculty of Teachers Training and Education, Universitas Kristen Satya Wacana. The data were gathered using the mindfulness scale and the life satisfaction scale. The results of the research showed that there had been positive and significant relationship between mindfulness and life satisfaction among the students of Guidance and Counseling Study Program, Faculty of Teachers Training and Education, Universitas Kristen Satya Wacana with the correlation coefficient rxy $=0.172$ and p 0.007 $(\mathrm{p}<0.01)$. The higher mindfulness score, the higher life satisfaction score, and vice versa.
\end{abstract}

Keywords: mindfulness; life satisfaction; guidance and counseling student

\begin{abstract}
Abstrak: Penelitian ini bertujuan untuk mengetahui hubungan antara mindfulness dengan kepuasan hidup mahasiswa Bimbingan dan Konseling. Jenis penelitian ini adalah penelitian korelasional dengan teknik analisis korelasi Kendall's Tau-b. Responden adalah 135 mahasiswa Bimbingan dan Konseling (BK), Fakultas Keguruan dan Ilmu Pendidikan (FKIP), Universitas Kristen Satya Wacana (UKSW). Data dikumpulkan dengan instrumen skala mindfulness dan skala kepuasan hidup. Hasil penelitian menunjukkan ada hubungan yang signifikan dengan arah positif antara mindfulness dengan kepuasan hidup mahasiswa BK FKIP UKSW dengan koefisien korelasi rxy $=0,172$ dan $p=0,007(p<0,01)$. Artinya, semakin tinggi skor mindfulness, maka akan semakin tinggi skor kepuasan hidup, begitu pula sebaliknya.
\end{abstract}

Kata kunci: mindfulness; kepuasan hidup; mahasiswa bimbingan dan konseling

Kepuasan hidup adalah penilaian umum individu terhadap kehidupannya (Diener, 2000). Penilaian ini sebagai tanda rasa puas individu (Diener, Kesebir, \& Lucas, 2008). Kepuasan secara umum meliputi: kepuasan terhadap kondisi yang dicita-citakan; kepuasan terhadap kondisi yang luar biasa; kepuasan terhadap perasaan bahagia; kepuasan terhadap hal-hal yang dianggap penting di dalam kehidupan; serta kepuasan yang ditandai dengan tidak ada hal di dalam kehidupan yang perlu untuk diubah oleh individu (van Beuningen, 2012). Kepuasan hidup bersifat subjektif dan berdampak positif bagi individu.

Kepuasan hidup merupakan salah satu komponen kesejahteraan subjektif (subjective wellbeing), selain sisi komponen afek positif dan negatif (Diener et al., 2008). Kepuasan hidup dilihat dari sisi kognitif dan kondisi sadar. Individu perlu menilai kehidupannya secara umum daripada hanya menilai di domain kepuasan yang spesifik pada proses evaluasi yang merefleksikan nilai dan tujuan keadaan individu dalam perspektif jangka panjang (Pavot \& Diener, 2009). Psikologi positif 
memasukkan kepuasan hidup sebagai pengalaman subjektif yang positif (Seligman, 2013). Pada psikologi positif, kepuasan hidup merupakan emosi positif di masa lalu dan merupakan ukuran dari topik kebahagiaan (Seligman, 2013). Rasa puas merupakan afektif, namun di dalam melakukan penilaian melibatkan unsur kognitif. Penilaian kepuasan hidup bersifat subjektif karena masingmasing individu memiliki kriterianya masing-masing.

Rutinitas kehidupan individu dapat berjalan secara otomatis tanpa melibatkan kesadaran dan perhatian penuh. Individu dapat mengerti dan merasakan kepuasan hidupnya dalam kondisi sadar. Keadaan otomatis tanpa kesadaran dan perhatian ini merupakan kondisi mindlessness, yaitu individu menolak hadir atau mengakui pikiran; emosi; motif; atau persepsi mengenai objek yang ada (Brown \& Ryan, 2003). Keadaan mindlessness menyebabkan berkurangnya kesadaran tiap momen yang menyebabkan hilangnya momen-momen yang dirasa puas oleh individu. Sebaliknya, mindfulness adalah sebuah keadaan penuh perhatian (attention) dan kesadaran (awareness) pada apa yang terjadi pada masa sekarang (Brown \& Ryan, 2003).

Mindfulness menghasilkan dampak yang positif dan berkontribusi langsung pada kesejahteraan (well-being) dan kebahagiaan (happiness) individu (Brown \& Ryan, 2003; Brown, Ryan, \& Creswell, 2007). Pada psikologi positif, mindfulness menjadi salah satu aspek kebahagiaan masa sekarang yaitu sebagai emosi positif masa kini (Arif, 2016). Ukuran kebahagiaan adalah kepuasan hidup individu, yaitu sebagai sebuah perasaan puas pada internal individu (Seligman, 2013; Uchida \& Oishi, 2016). Kepuasan hidup sebagai tolok ukur kebahagiaan dapat muncul dari mindfulness karena mindfull menciptakan kejernihan kesadaran, kesadaran yang tidak membuat konsep dan tidak membeda-bedakan, kesadaran dan perhatian yang fleksibel, dapat memiliki pendirian yang empiris terhadap realitas, sadar berorientasi pada masa sekarang, dan perhatian serta kesadaran yang stabil dan berkelanjutan (Brown et al., 2007). Individu dapat menerima pengalaman sebagai realitas apa adanya, hal ini dapat mereduksi perasaan negatif dan meningkatkan perasaan positif pada individu.

Hasil penelitian menunjukkan adanya hubungan positif yang signifikan dengan arah positif antara mindfulness dengan afek menyenangkan, afek positif, kepercayaan diri dan rasa optimis, serta memiliki hubungan negatif yang signifikan dengan afek tidak menyenangkan, afek negatif, kecemasan, depresi, dan neurotik (Brown \& Ryan, 2003). Hubungan negatif yang signifikan juga ditunjukkan antara mindfulness dengan sub variabel dari pikiran otomatis negatif yaitu frekuensi depresi, ketakutan, dan ketakutan sosial yang berhubungan dengan kognitif (Akin, 2012; Frewen, Evans, Maraj, Dozois, \& Partridge, 2008), sedangkan hubungan positif yang signifikan ditunjukkan antara mindfulness dengan kemampuan untuk "letting go" terhadap pikiran negatif (Frewen et al., 2008).

Kehidupan dengan mindfulness sangat penting dan berdampak pada tingkat kebahagiaan pada pekerja sosial (Shier \& Graham, 2011). Hal ini karena ada hubungan negatif yang signifikan antara mindfulness dan kecerdasan emosi terhadap burnout (Testa \& Sangganjanavanich, 2016). Mindfulness dan kontrol diri juga saling berhubungan secara positif dengan kesejahteraan psikologis dan berhubungan negatif dengan gejala gangguan psikologis (Bowlin \& Baer, 2012). Mindfulness juga memiliki hubungan positif yang signifikan dengan konstruk yang berhubungan dengan kebahagiaan (kesejahteraan psikologis), self-compassion, persetujuan, dan keterbukaan; serta berhubungan negatif yang signifikan dengan neurotik (Hollis-Walker \& Colosimo, 2011). Terkait dengan kepuasan hidup pada domain finansial, mindfulness membuat kepuasan hidup tidak selalu berpatok pada finansial (Brown, Kasser, Ryan, Linley, \& Orzech, 2009).

Pengajaran meditasi mindfulness berpengaruh dengan penurunan pikiran otomatis negatif yang memprediksi meningkatnya kepuasan hidup (Ritvo et al., 2013). Mindfulness juga memiliki pengaruh yang signifikan terhadap kesejahteraan psikologis (Pidgeon \& Keye, 2014); memiliki pengaruh positif yang signifikan terhadap setiap dimensi kesejahteraan psikologis pada remaja (Savitri \& Listiyandini, 2017). Efek variabel mediator juga memiliki pengaruh pada hubungan antara mindfulness dengan variabel-variabel yang terkait dengan kepuasan hidup individu diantaranya adalah resiliensi (Bajaj \& Pande, 2016); regulasi emosi (Mandal, Arya, \& Pandey, 2017); serta kecerdasan emosi (Wang \& Kong, 2014). 
Selain hubungan antara mindfulness dengan kepuasan hidup yang dipacu oleh variabel moderator. Mindfulness dapat juga menjadi variabel moderator yang memengaruhi hubungan antar variabel lain yang berdampak positif pada individu. Rendahnya mindfulness berhubungan dengan prokrastinasi dan stres; dan juga prokrastinasi memengaruhi penyesuaian kesehatan fisik dan mental (Sirois \& Tosti, 2012). Mindfulness juga menjadi variabel moderator signifikan pada hubungan antara kontrol diri dengan gejala gangguan psikologis (Bowlin \& Baer, 2012). Berdasarkan kajian penelitian, mindfulness memiliki hubungan dengan kualitas hidup individu (Sari \& Yulianti, 2017). Mindfulness dapat berhubungan dengan hal-hal positif pada individu sehingga mengindikasikan kepuasan hidup. Peran mindfulness memiliki dampak yang positif pada individu yang menciptakan rasa puas pada kehidupan sehingga individu terlepas dari ketidaknyamanan yang dialaminya.

Kajian hasil penelitian menunjukkan bahwa mindfulness berhubungan dengan kepuasan hidup, namun ada beberapa penelitian yang menunjukkan hasil berbeda. Sebuah penelitian menunjukkan adanya hubungan positif yang signifikan antara mindfulness dengan kepuasan hidup (Brown \& Ryan, 2003), sedangkan penelitian lainnya tidak menemukan adanya hubungan yang signifikan antara mindfulness dengan kepuasan hidup (Collard, Avny, \& Boniwell, 2008). Penelitian ulang perlu dilakukan untuk memastikan signifikansi hubungan antara mindfulness dengan kepuasan hidup.

Responden penelitian ini adalah mahasiswa aktif program studi BK FKIP UKSW. Mahasiswa BK dipilih sebagai responden dalam penelitian ini karena mindfulness memiliki manfaat untuk mengembangkan hubungan terapeutik; empati; rasa belas kasih; keterampilan konseling; menurunkan stres dan kecemasan; meningkatkan orientasi masa kini; serta meningkatkan kesadaran dan penerimaan terhadap kondisi perasaan dan tubuh yang bersitegang (Davis \& Hayes, 2011; Felton, Coates, \& Christopher, 2015; Fulton, 2016).

Tujuan penelitian ini adalah untuk mengetahui signifikansi hubungan antara mindfulness dengan kepuasan hidup pada mahasiswa BK FKIP UKSW. Berdasarkan kajian riset relevan yang ada, mindfulness memiliki hubungan erat dengan kepuasan hidup, maka hipotesis penelitian ini adalah "ada hubungan yang signifikan antara mindfulness dengan kepuasan hidup mahasiswa BK FKIP UKSW."

\section{METODE}

Penelitian korelasional ini bertujuan membuktikan ada tidaknya hubungan yang signifikan antara variabel mindfulness dengan variabel kepuasan hidup. Variabel bebas (x) dalam penelitian ini adalah mindfulness, sedangkan variabel terikat (y) dalam penelitian ini adalah kepuasan hidup.

Populasi subjek penelitian ini sejumlah 218 orang mahasiswa aktif program studi BK FKIP UKSW. Pengambilan sampel menggunakan teknik proportionate stratified random sampling yaitu sampel diambil sesuai proporsi, sebanding dengan populasi per-strata dari masing-masing mahasiswa tiap-tiap angkatan mulai dari 2014 s/d 2017 sehingga diperoleh sampel sejumlah 135 orang.

Instrumen yang digunakan untuk pengumpulan data dalam penelitian ini adalah The Mindfulness Attention and Awareness Scale (MAAS) (Brown \& Ryan, 2003) untuk mengukur variabel mindfulness. Untuk mengukur variabel kepuasan hidup, kami menggunakan Satisfaction With Life Scale (SWLS) (Diener, Emmons, Larsen, \& Griffin, 1985). Peneliti melakukan adaptasi instrumen MAAS dan SWLS ke dalam Bahasa Indonesia dengan prosedur back translation oleh Limpid Sesty Lupiani, mahasiswa program studi Pendidikan Bahasa Inggris Fakultas Bahasa dan Seni UKSW.

MAAS yang mengacu pada teori mindfulness (Brown \& Ryan, 2003) merupakan skala untuk mengukur absennya perhatian (attention) dan kesadaran (awareness) pada mindfulness yang disusun dalam 15 butir. Koefisien Cronbach Alpha instrumen MAAS pada mahasiswa adalah $\alpha=$ $0,82(\mathrm{n}=327)$. Koefisien korelasi Item-Total Correlation bergerak dari 0,25 s/d 0,73 ( $\mathrm{n}=313)$. $M A A S$ menggunakan skala Likert dengan kemungkinan jawaban yaitu $1=$ Almost Always; $2=$ Very Frequently; 3 = Somewhat Frequenly; 4 = Somewhat Infrequently; 5 = Very Infrequently; 6 = Almost Never. Format jawaban $M A A S$ diubah oleh peneliti menjadi empat kemungkinan jawaban karena menyesuaikan responden Indonesia yang mengalami kesulitan dalam penilaian dengan enam 
alternatif jawaban. Respon jawaban $M A A S$ yang digunakan dalam penelitian ini adalah: Hampir Selalu (HS) diberi skor 1; Sering (S) diberi skor 2; Jarang (J) diberi skor 3; Hampir Tidak Pernah (HTP) diberi skor 4.

SWLS yang mengacu pada teori subjective well-being (Diener et al., 1985) merupakan skala untuk mengukur kepuasan hidup secara umum yang disusun dalam lima butir. Koefisien Cronbach Alpha instrumen SWLS bagi mahasiswa adalah $\alpha=0,87$. Koefisien Item-Total Correlation SWLS bergerak dari 0,57 s/d 0,75 $(\mathrm{n}=25)$ dan 0,61 s/d 0,81 $(\mathrm{n}=125)$. SWLS menggunakan skala Likert dengan tujuh kemungkinan jawaban yaitu $1=$ Strongly Disagree $; 2=$ Disagree; $3=$ Slightly Disagree; $4=$ Neither Agree nor Disagree; $5=$ Slightly Agree; $6=$ Agree; $7=$ Strongly Agree. Format respon jawaban $S W L S$ diubah oleh peneliti menjadi empat kemungkinan jawaban karena menyesuaikan responden di Indonesia yang mengalami kesulitan dalam penilaian dengan tujuh alternatif jawaban. Kemungkinan jawaban SWLS adalah: Sangat Tidak Setuju (STS) diberi skor 1; Tidak Setuju (TS) diberi skor 2; Setuju (S) diberi skor 3; Sangat Setuju (SS) diberi skor 4.

Uji coba instrumen $M A A S$ dan $S W L S$ dilakukan pada responden mahasiswa BK secara acak $(\mathrm{n}=30)$. Hasil uji reliabilitas MAAS menunjukkan koefisien Alpha Croncbach $(\alpha)=0,722$. Uji validitas butir instrumen MAAS menggunakan Corrected-Item-Total Correlation menghasilkan koefisien korelasi butir yang bergerak dari 0,178-0,699. Hasil uji reliabilitas $S W L S$ menghasilkan koefisien Alpha Croncbach =0,629. Uji validitas butir instrumen $S W L S$ menggunakan CorrectedItem-Total Correlation dengan koefisien korelasi butir yang bergerak dari 0,172-0,627. Hasil uji coba instrumen dapat dinyatakan valid dan reliabel sehingga dapat digunakan dalam penelitian ini (International Test Commission (ITC), 2018).

Pengambilan data menggunakan instrumen dilakukan pada saat jam kuliah yang terdapat di masing-masing angkatan pada semester dua, tahun perkuliahan 2017-2018 dengan menjumlahkan data uji coba instrumen $(n=30)$ dan data saat penelitian $(n=105)$. Sebelum melakukan pengisian instrumen, peneliti memberikan penjelasan singkat mengenai mindfulness dan kepuasan hidup.

Teknik analisis data menggunakan analisis deskriptif dan analisis statistik. Analisis statistik yang digunakan dalam penelitian ini adalah analisis korelasional. Rumus korelasi Kendall's Tau-b digunakan untuk mencari hubungan dan menguji hipotesis antara dua variabel atau lebih bila datanya berbentuk ordinal. Analisis data menggunakan bantuan perangkat lunak IBM SPSS 20.0 for Windows.

\section{HASIL}

Hasil penelitian ini berupa hasil analisis deskriptif dan analisis statistik. Hasil analisis data deskriptif masing-masing variabel disajikan pada tabel 1 dan tabel 2. Sebagian besar mahasiswa BK FKIP UKSW memiliki tingkat mindfulness dalam kategori sedang $(61,5 \%)$, dengan rata-rata jarak penyimpangan titik-titik data yang diukur dari nilai rata-rata data variabel mindfulness (standar deviation) 4,4740 (Tabel 1). Untuk variabel kepuasan hidup, sebagian besar mahasiswa BK FKIP UKSW memiliki tingkat kepuasan hidup dalam kategori agak tinggi (58,5\%), dengan rata-rata jarak penyimpangan titik-titik data yang diukur dari nilai rata-rata data variabel mindfulness (standar deviation) 2,083 (Tabel 2). Hasil analisis korelasional mindfulness dengan kepuasan hidup pada mahasiswa BK FKIP UKSW menggunakan rumus Kendall's Tau-b dengan bantuan perangkat lunak IBM SPSS 20.0 for Windows disajikan dalam tabel 3.

Hasil analisis menggunakan teknik Kendall's Tau-b dengan bantuan perangkat lunak SPSS 20.0 for Windows menunjukkan hasil koefisien korelasi antara mindfulness dengan kepuasan hidup yaitu rxy $=0,172$ dan $\mathrm{p}=0,007$. Berpedoman pada taraf signifikansi $1 \%$ dengan tingkat kepercayaan $99 \%$ didapatkan $\mathrm{p}=0,007<0,01$ artinya ada hubungan yang signifikan dengan arah positif antara mindfulness dengan kepuasan hidup pada mahasiswa BK FKIP UKSW. Artinya, semakin tinggi skor mindfulness, maka akan semakin tinggi skor kepuasan hidupnya, demikian pula sebaliknya semakin rendah skor mindfulness, maka akan semakin rendah skor kepuasan hidupnya. 
Tabel 1 Kategori Variabel Mindfulness

\begin{tabular}{cccc}
\hline Range & Kategori & Frekuensi & Persentase \\
\hline $51-60$ & Tinggi & 2 & $1,5 \%$ \\
$42-50$ & Agak Tinggi & 42 & $31,1 \%$ \\
$33-41$ & Sedang & 83 & $61,5 \%$ \\
$24-32$ & Agak Rendah & 8 & $5,9 \%$ \\
$15-23$ & Rendah & 0 & $0 \%$ \\
& Total & $\mathbf{1 3 5}$ & $\mathbf{1 0 0} \%$ \\
Mean & 39,59 & \\
Std. Deviation & 4,4740 & \\
Minimum & 25 & \\
Maksimum & 53 & \\
\hline
\end{tabular}

Tabel 2 Kategori Variabel Kepuasan Hidup

\begin{tabular}{cccc}
\hline Range & Kategori & Frekuensi & Persentase \\
\hline $17-20$ & Tinggi & 15 & $11,1 \%$ \\
$14-16$ & Agak Tinggi & 79 & $58,5 \%$ \\
$11-13$ & Sedang & 33 & $24,4 \%$ \\
$8-10$ & Agak Rendah & 8 & $5,9 \%$ \\
$5-7$ & Rendah & 0 & $0 \%$ \\
& Total & $\mathbf{1 3 5}$ & $\mathbf{1 0 0} \%$ \\
& Mean & 14,11 & \\
Std. Deviation & 2,083 & \\
Minimum & 8 & \\
Maksimum & 19 & \\
& &
\end{tabular}

Tabel 3 Uji Korelasional Mindfulness dengan Kepuasan Hidup

\begin{tabular}{|c|c|c|c|c|}
\hline \multicolumn{5}{|c|}{ Correlations } \\
\hline & & & Mindfulness & Kepuasan Hidup \\
\hline \multirow[t]{6}{*}{ Kendall's tau_b } & Mindfulness & Correlation Coefficient & 1.000 & $.172 * *$ \\
\hline & & Sig. (2-tailed) & . & .007 \\
\hline & & $N$ & 135 & 135 \\
\hline & Kepuasan & Correlation Coefficient & $.172 * *$ & 1.000 \\
\hline & Hidup & Sig. (2-tailed) & .007 & . \\
\hline & & $N$ & 135 & 135 \\
\hline
\end{tabular}

**. Correlation is significant at the 0.01 level (2-tailed).

Hasil analisis menunjukkan bahwa ada hubungan yang signifikan antara mindfulness dengan kepuasan hidup mahasiswa program studi BK FKIP UKSW, maka hipotesis "ada hubungan yang signifikan antara mindfulness dengan kepuasan hidup pada mahasiswa BK FKIP UKSW" dapat diterima. 


\section{PEMBAHASAN}

Hasil penelitian menunjukkan bahwa ada hubungan yang signifikan antara mindfulness dengan kepuasan hidup mahasiswa BK FKIP UKSW, artinya semakin tinggi skor mindfulness, maka akan semakin tinggi skor kepuasan hidupnya, demikian pula sebaliknya. Koefisien korelasi hubungan antara mindfulness dengan kepuasan hidup adalah sangat rendah $(\mathrm{rxy}=0,172)$. Artinya, kepuasan hidup juga berhubungan dengan faktor-faktor lain selain mindfulness yang terdapat pada faktor emosi positif antara lain: keterlibatan individu; relasi yang positif; makna hidup; dan pencapaian (Arif, 2016).

Mindfulness menunjukkan kualitas berkesadaran yang jelas pada pengalaman saat ini yang berlawanan dengan kondisi mindlesness yang merupakan keadaan kurang terjaga dari sebuah kebiasaan atau fungsi otomatis individu yang dapat membuat individu kronis (Brown \& Ryan, 2003). Proses penilaian kepuasan hidup dilakukan oleh individu pada kondisi sadar dimana kriteria penilaiannya menurut laporan diri masing-masing individu (Pavot \& Diener, 2009). Artinya, kepuasan hidup dimengerti dan dirasakan oleh individu pada saat kondisi sadar. Kesadaran menciptakan perhatian individu terhadap momen pengalaman yang menyebabkan individu menyadari kepuasan hidupnya, sehingga terciptalah hubungan yang signifikan antara mindfulness dengan kepuasan hidup.

Adanya hubungan antara variabel mindfulness dan kepuasan hidup disebabkan keduanya terletak pada faktor emosi positif. Mindfulness terletak pada emosi positif masa sekarang dan kebahagiaan masa sekarang (Seligman, 2004; Arif, 2016), sedangkan kepuasan hidup terletak pada emosi positif masa lalu (Seligman, 2004). Kepuasan hidup di masa lalu diterima sebagai kebahagiaan pada masa kini. Mindfulness menerima pengalaman sebagaimana adanya "as they are" (Brown \& Ryan, 2003) sehingga pengalaman masa lalu yang dirasakan atau terlintas di pikiran pada masa kini akan diterima oleh individu sebagai kenyataan.

Terdapat hubungan positif yang signifikan dengan afek positif serta ada hubungan negatif yang signifikan dengan afek negatif (Brown \& Ryan, 2003). Afek negatif dapat memengaruhi ketidakjernihan individu dalam menilai kepuasan hidup. Mindfulness hanya sebatas mengobservasi afek negatif dan mengarahkannya kepada penerimaan. Kepuasan hidup pada individu muncul karena penerimaan individu terhadap setiap pengalaman yang telah dilaluinya, hal ini karena mindfulness meningkatkan kemampuan individu untuk "letting go" terhadap masa lalunya. Hidup adalah tentang di sini dan saat ini saja (Hanh, 2014). Mindfulness menciptakan penekanan emosi positif pada masa kini. Hasil penelitian ini sesuai dan sejalan dengan teori yang menyebutkan bahwa mindfulness berkontribusi pada kesejahteraan (well-being) dan kebahagiaan (happiness) karena kepuasan hidup adalah salah satu indikatornya (Brown \& Ryan, 2003). Hasil penelitian ini juga sesuai dengan penelitian lain yang menunjukkan ada hubungan positif yang signifikan antara mindfulness dengan kepuasan hidup (Brown \& Ryan, 2003).

Penelitian lain menunjukkan hasil yang berbeda, yaitu tidak ada hubungan yang signifikan antara mindfulness dengan kepuasan hidup (Collard et al., 2008). Adanya hubungan positif yang signifikan antara mindfulness dengan kepuasan hidup membuat mindfulness dapat diaplikasikan dalam bidang BK.

Mindfulness telah menarik perhatian sebagai alat untuk mengembangkan hubungan terapeutik konselor serta meningkatkan efektivitas pendidikan konselor (Fulton, 2016). Mindfulness juga memiliki manfaat untuk mengembangkan hubungan terapeutik; empati; rasa belas kasih; keterampilan konseling; menurunkan stres dan kecemasan; meningkatkan orientasi masa kini, serta meningkatkan kesadaran dan penerimaan terhadap kondisi perasaan dan tubuh yang bersitegang (Davis \& Hayes, 2011; Felton et al., 2015; Fulton, 2016). Peningkatan kepuasan hidup dapat dilakukan melalui pemberian pelatihan program mindfulness untuk mahasiswa BK sebagai indikator kebahagiaan pada individu.

Peneliti selanjutnya dapat melakukan desain penelitian eksperimen untuk menunjukkan hasil peningkatan maupun penurunan skor kepuasan hidup pada individu dengan menggunakan meditasi mindfulness formal atau informal (Mace, 2007); maupun mindfulness berbasis intervensi (Hanley, Abell, Osborn, Roehrig, \& Canto, 2016). Praktik formal meliputi sitting meditations (pemusatan 
perhatian pada pernafasan; sensasi tubuh; suara; pikiran; dan sebagainya), movement meditations (meditasi berjalan; peregangan dengan mindful yoga); serta group exchange (penugasan; diskusi terpimpin tentang pengalaman mindful). Praktik informal meliputi mindful activity (mindful ketika makan; membersihkan sesuatu; mengendarai kendaraan bermotor; dan sebagainya); pemberian tugas terstruktur (self-monitoring; problem solving; dan sebagainya); mindful reading (khususnya membaca puisi); serta mini-meditations (contohnya seperti ' 3 minute breathing space'). Mindfulness berbasis intervensi antara lain: mindfulness-based stress reduction; mindfulness-based cognitive therapy; dialectical behaviour therapy; serta acceptance and commitment therapy. Meditasi maupun pendekatan mindfulness akan berdampak pada hasil peningkatan maupun penurunan skor kepuasan hidup.

Penelitian ini memiliki kelebihan dan kekurangan. Kelebihan penelitian ini adalah menggunakan responden dari Asia yang merupakan wilayah asal mindfulness diadopsi menjadi sekuler, sehingga melengkapi hasil penelitian yang sebelumnya telah dilakukan di Amerika (Brown \& Ryan, 2003) serta di Inggris (Collard et al., 2008). Kekurangan dari penelitian ini adalah peneliti hanya menggunakan aspek tunggal kesadaran dan perhatian dari mindfulness (Brown \& Ryan, 2003), yang mengukur pada pengalaman sehari-hari. Aspek lain dari mindfulness yang dapat diteliti antara lain: observing (mengamati); describing (memperikan); acting with awareness (bertindak dengan kesadaran); non judging of inner experience (tidak menghakimi pengalaman batin); dan non reactivitiy to inner experience (tidak bereaksi terhadap pengalaman) (Baer et al., 2008). Penelitian ini juga hanya mengukur salah satu variabel dari kesejahteraan maupun kebahagiaan, yaitu kepuasan hidup. Hal ini dikarenakan penelitian berangkat dari adanya hasil perbedaan temuan penelitian Brown \& Ryan (2003) yang berbeda dengan hasil penelitian Collard et al., (2008) dalam mengetahui hubungan antara mindfulness dengan aspek kesejahteraan pada variabel kepuasan hidup.

\section{SIMPULAN}

Hasil penelitian menunjukkan ada hubungan yang signifikan antara mindfulness dengan kepuasan hidup mahasiswa program studi BK FKIP UKSW. Artinya, semakin tinggi skor mindfulness, maka semakin tinggi skor kepuasan hidupnya, dan semakin rendah skor mindfulness, maka semakin rendah skor kepuasan hidupnya. Mindfulness dapat diaplikasikan pada calon konselor agar mengalami kepuasan hidup sebagai tanda kebahagiaan. Kondisi mindful dan kepuasan hidup dapat membantu calon konselor dalam membangun hubungan konseling yang efektif.

\section{DAFTAR RUJUKAN}

Akin, A. (2012). Self-compassion and Automatic Thoughts. Hacettepe Üniversitesi Eğitim Fakültesi Dergisi, 42, 1-10.

Arif, I. S. (2016). Psikologi Positif: Pendekatan Saintifik Menuju Kebahagiaan. Jakarta: Gramedia Pustaka Utama.

Baer, R.A., Smith, G. T., Lykins, E., Button, D., Krietemeyer, J., Sauer, S., .. Williams, J. M. G. (2008). Construct Validity of the Five Facet Mindfulness Questionnaire in Meditating and Nonmeditating Samples. Assessment, 15(3), 329-342. https://doi.org/10.1177/1073191107313003

Bajaj, B., \& Pande, N. (2016). Mediating Role of Resilience in The Impact of Mindfulness on Life Satisfaction and Affect As Indices of Subjective Well-being. Personality and Individual Differences, 93, 63-67. https://doi.org/10.1016/j.paid.2015.09.005

Bowlin, S. L., \& Baer, R. A. (2012). Relationships Between Mindfulness, Self-control, and Psychological Functioning. Personality and Individual Differences, 52(3), 411-415. https://doi. org/10.1016/j.paid.2011.10.050

Brown, K. W., Kasser, T., Ryan, R. M., Linley, P. A., \& Orzech, K. (2009). When What One Has is Enough: Mindfulness, Financial Desire Discrepancy, and Subjective Well-being. Journal of Research in Personality, 43(5), 727-736. https://doi.org/10.1016/j.jrp.2009.07.002 
Brown, K. W., \& Ryan, R. M. (2003). The Benefits of Being Present: Mindfulness and Its Role in Psychological Well-being. Journal of Personality and Social Psychology, 84(4), 822-848. https://doi.org/10.1037/0022-3514.84.4.822

Brown, K. W., Ryan, R. M., \& Creswell, J. D. (2007). Mindfulness: Theoretical Foundations and Evidence for Its Salutary Effects. Psychological Inquiry, 18(4), 211-237. https://doi. org/10.1080/10478400701598298

Collard, P., Avny, N., \& Boniwell, I. (2008). Teaching Mindfulness Based Cognitive Therapy (MBCT) to Students: The Effects of MBCT on The Levels of Mindfulness and Subjective Wellbeing. Counselling Psychology Quarterly, 21(4), 323-336.

Davis, D. M., \& Hayes, J. A. (2011). What are The Benefits of Mindfulness? A Practice Review of Psychotherapy-related Research. Psychotherapy, 48(2), 198-208. https://doi.org/10.1037/ a0022062

Diener, E. (2000). Subjective Well-being: The Science of Happiness and A Proposal for A National Index. American Psychologist, 55(1), 34-43. https://doi.org/10.1037/0003-066X.55.1.34

Diener, E., Emmons, R. A., Larsen, R. J., \& Griffin, S. (1985). The Satisfaction With Life Scale. Journal of Personality Assessment, 49(1), 71-75. https://doi.org/10.1207/s15327752jpa4901_13

Diener, E., Kesebir, P., \& Lucas, R. (2008). Benefits of Accounts of Well-Being - For Societies and for Psychological Science. Applied Psychology, 57(s1), 37-53. https://doi.org/10.1111/j.14640597.2008.00353.x

Felton, T. M., Coates, L., \& Christopher, J. C. (2015). Impact of Mindfulness Training on Counseling Students' Perceptions of Stress. Mindfulness, 6(2), 159-169. https://doi.org/10.1007/s12671013-0240-8

Frewen, P. A., Evans, E. M., Maraj, N., Dozois, D. J. A., \& Partridge, K. (2008). Letting Go: Mindfulness and Negative Automatic Thinking. Cognitive Therapy and Research, 32(6), 758774. https://doi.org/10.1007/s10608-007-9142-1

Fulton, C. L. (2016). Mindfulness, Self-Compassion, and Counselor Characteristics and Session Variables. Journal of Mental Health Counseling, 38(4), 360-374. https://doi.org/10.17744/ mehc.38.4.06

Hanh, T. N. (2014). Happiness and Peace Are Possible. Dalam The Mindfulness Sampler: Shambhala Authors on the Power of Awareness in Daily Life. Boston, MA: Shambhala Publications, Inc.

Hanley, A. W., Abell, N., Osborn, D. S., Roehrig, A. D., \& Canto, A. I. (2016). Mind the Gaps: Are Conclusions About Mindfulness Entirely Conclusive? Journal of Counseling \& Development, 94(1), 103-113. https://doi.org/10.1002/jcad.12066

Hollis-Walker, L., \& Colosimo, K. (2011). Mindfulness, Self-compassion, and Happiness in NonMeditators: A Theoretical and Empirical Examination. Personality and Individual Differences, 50(2), 222-227. https://doi.org/10.1016/j.paid.2010.09.033

International Test Commission (ITC). (2018) ITC Guidelines for Translating and Adapting Tests (Second Edition). International Journal of Testing, 18(2), 101-134. https://doi.org/10.1080/15 305058.2017.1398166

Mace, C. (2007). Mindfulness and Mental Health: Therapy, Theory and Science. Routledge.

Mandal, S. P., Arya, Y. K., \& Pandey, R. (2017). Mindfulness, Emotion Regulation, and Subjective Well-Being: Exploring the Link. SIS Journal of Projective Psychology \& Mental Health, 24(1), $57-63$.

Pavot, W., \& Diener, E. (2009). Review of the Satisfaction With Life Scale (hal. 101-117). https:// doi.org/10.1007/978-90-481-2354-4_5

Pidgeon, A., \& Keye, M. (2014). Relationship between Resilience, Mindfulness, and Psychological Well-being in University Students. International Journal of Liberal Arts and Social Science, 2(5), 27-32. 
Ritvo, P., Vora, K., Irvine, J., Mongrain, M., Azargive, S., Azam, M. A., ... Cribbie, R. (2013). Reductions in Negative Automatic Thoughts in Students Attending Mindfulness Tutorials Predicts Increased Life Satisfaction. IJEP - International Journal of Educational Psychology, 2(3), 272-296. https://doi.org/10.4471/ijep.2013.28

Sari, R. A., \& Yulianti, A. (2017). Mindfullness Dengan Kualitas Hidup pada Lanjut Usia. Jurnal Psikologi UIN Sultan Syarif Kasim, 13(1), 48-54.

Savitri, W. C., \& Listiyandini, R. A. (2017). Mindfulness dan Kesejahteraan Psikologis pada Remaja. Psikohumaniora: Jurnal Penelitian Psikologi, 2(1), 43-59. https://doi.org/10.21580/ pjpp.v2i1.1323

Seligman, M. E. P. (2013). Beyond Authentic Happiness, Menciptakan Kebahagiaan Sempurna dengan Psikologi Positif. Bandung: Kaifa.

Seligman, M. E. P. (2004). Authentic Happiness: Using the New Positive Psychology to Realize Your Potential for Lasting Fulfillment. Simon and Schuster.

Shier, M. L., \& Graham, J. R. (2011). Mindfulness, Subjective Well-Being, and Social Work: Insight into Their Interconnection from Social Work Practitioners. Social Work Education, 30(1), 29 44. https://doi.org/10.1080/02615471003763188

Sirois, F. M., \& Tosti, N. (2012). Lost in The Moment? An Investigation of Procrastination, Mindfulness, and Well-being. Journal of Rational-Emotive \& Cognitive-Behavior Therapy, 30(4), 237-248. https://doi.org/10.1007/s10942-012-0151-y

Testa, D., \& Sangganjanavanich, V. F. (2016). Contribution of Mindfulness and Emotional Intelligence to Burnout Among Counseling Interns. Counselor Education and Supervision, 55(2), 95-108. https://doi.org/10.1002/ceas.12035

Uchida, Y., \& Oishi, S. (2016). The Happiness of Individuals and The Collective. Japanese Psychological Research, 58(1), 125-141. https://doi.org/10.1111/jpr.12103

van Beuningen, J. (2012). The Satisfaction with Life Scale Examining Construct Validity. The Hague: Statistics Netherlands.

Wang, Y., \& Kong, F. (2014). The Role of Emotional Intelligence in the Impact of Mindfulness on Life Satisfaction and Mental Distress. Social Indicators Research, 116(3), 843-852. https://doi. org/10.1007/s11205-013-0327-6 